\title{
Seed longevity studies in wild type, cultivated and inter-specific recombination inbred lines (RILs) of soybean
}

\section{Subhash Chandra}

ICAR Indian Institute of Soybean Research

Akshay Talukdar ( $\nabla$ akshay.talukdar1@gmail.com )

Indian Agricultural Research Institute, New Delhi https://orcid.org/0000-0002-8936-4147

Yashpal Taak

ICAR-Indian Agricultural Research Institute, New Delhi

\section{Raju R. Yadav}

ICAR-Indian Agricultural Research Institute, New Delhi, India

Manisha Saini

ICAR-Indian Agricultural Research Institute, New Delhi

\section{N. S. Sipani}

CORC-Sipani Krishi Anusandhan Farm, Mandsaur, MP, India

\section{Research Article}

Keywords: Genetic resource, Seed longevity, Wild soybeans, Germination, RILs, Diversity

Posted Date: March 2nd, 2021

DOI: https://doi.org/10.21203/rs.3.rs-216517/v1

License: @ (i) This work is licensed under a Creative Commons Attribution 4.0 International License. Read Full License

Version of Record: A version of this preprint was published at Genetic Resources and Crop Evolution on July 6th, 2021. See the published version at https://doi.org/10.1007/s10722-021-01240-2. 


\section{Abstract}

Loss of seed viability is a serious hurdle in higher production and ambient seed storage of soybean. Understanding the factors affecting seed viability and identification of soybean genotype(s) with higher viability is critical for higher soybean production. In this study, seeds of 125 soybean genotypes of three different species (Glycine tomentella, Glycine soja and Glycine max) and 25 RILs (Glycine soja $\times$ Glycine soja) were tested for germination immediately after harvest followed by one, two and three years of ambient storage. Fresh seeds of all the genotypes recorded $78-99 \%$ germination with a mean of $94.02 \%$. However, the mean value of per cent germination of all the genotypes after one, two and three years of ambient storage decreased and found to stand at $79.51 \%, 52.24 \%$ and $29.18 \%$, respectively. Among the genotypes tested, $G$. tomentella accession registered highest seed storability followed by G. soja, RILs and G. max. After three years of storage, 14 wild type genotypes and 3 RILs maintained $>70 \%$ germination and identified as 'good storers'. Genetic divergence studies via k-mean clustering and principal component analysis grouped all genotypes in three cluster/component based on seed size, seed coat permeability and seed viability. Seed viability was significantly and negatively correlated with electrical conductivity. Good storers found to be having slow imbibition rate than poor storers in initial hours of imbibition. The good storing genotypes identified in this study will serve as an elite soybean genetic resource in developing the soybean cultivars with better seed longevity.

\section{Introduction}

Soybean (Glycine max L. Merrill) is world's one of the most important oilseed crop for food, feed and industrial utilities. Owing to its multifarious utilities including medicinal and cosmetic applications, demand for soybean is increasing worldwide. It is found to be the cheapest source of vegetable oil, and protein. Considering the power, properties and limitless applications, the soybean has been christened as the 'Golden bean' (Adsul et al. 2018). However, viability of the soybean seed is a serious concern for the farmers and traders; it rapidly loses viability during ambient storage more severely in the tropic and sub-tropics (Hang et al. 2015), which severely affects seedling vigour, crop stand in the field and eventual yield. The viability is highly influenced by genetic factors, physiological maturity, handling and processing practices and storage conditions (Zhang et al. 2019). High relative humidity and temperature accelerates the deterioration asking for higher seed rate for maintaining the crop stand in the field. Therefore, it is prudent to understand the seed deterioration mechanism so as to develop soybean varieties that can withstand the stresses and maintain viability of the seeds during ambient storage.

Existence of large genotypic variations for traits that affects seed viability has been reported in soybean (Glycine max L. Merrill) including factors such as mechanical damages (Zahid, 2013), field weathering (Bhatia, 1996), physiological characteristics like imbibition kinetics and electrolyte leaching (Kuchlan et al. 2010; Hosamani et al. 2013; Sooganna et al. 2016). The seed traits that enhances seed viability includes hard seed coat (Kumar et al., 2019a), small seed size (Hosamani et al. 2013 ), black seed coat (Liu et al. 2017) and tight attachment of the seed coat to the cotyledons (Kuchlan et al. 2010). Typically wild type soybean seeds remain viable for longer duration than the cultivated type (Chandra et al. 2017). Attempts have also been made to identify molecular markers linked to the traits considered to influence viability traits (Dargahi et al. 2014; Kumar et al. 2019b; Zhang et al. 2019).

Inconsistency in the results of various seed viability related studies is not uncommon. Causes of such discrepancies include variation in tested genotypes, populations used, approached followed, criteria adopted, etc. (Chandra et al. 2020) The studies reported earlier have had used seeds stored for one or two years only. Further, no reports could be found where wild type soybeans viz. $G$ soja and $G$ tomentella were used to understand the viability mechanisms of the seeds in comparison to $G$ max. Why the seeds of wild type soybean survive longer than others is not clearly known. Therefore, the present study envisaged investigating the longevity of the soybean using the seeds of wild type, cultivated type and inter-specific RILs stored for one to three years under ambient storage conditions. Genotypic variability for the traits related to seed viability was also investigated for various soybean genotypes.

\section{Materials And Methods}

\section{Plant material}


The experimental material (seeds) used for evaluation of seed longevity and its associated traits was comprised of 150 soybean genotypes (Supplementary Table 1) that included one accession of Glycine tomentella, a perennial species of soybean; 19 accessions of Glycine soja, immediate progenitor of cultivated soybean (G. max); 105 genotypes of Glycine max and 25 interspecific recombinant inbred lines (RILs) produced by crossing $G$ soja accession DC2008-1 and G max genotypes DS9712.

\section{Assay of seed germination and associated traits}

Fresh seeds of each soybean species were harvested carefully and maintained with uniform moisture content prior to storage. The seeds of each genotype were packed in water proof brown paper seed envelops and kept under ambient storage condition (average $25 \pm 5^{\circ} \mathrm{C}$ and $65 \pm 5 \% \mathrm{RH}$ ). At start of seed storage, associated traits to seed viability viz., seed coat colour, 100 seed weight and seed coat permeability (slow imbibition approach) for the entire soybean lots were recorded using standard methodologies as per Chandra et al. (2017).

During the storage period, seed samples were drawn at one-year interval for 3 years and tested for viability through germination. The germination of the seeds was tested as per ISTA rules (Anon, 2013) following between-paper roll towel method at $25^{\circ} \mathrm{C}$ in three replications of 100 seeds each. The seeds of the $G$ soja and $G$ tomentella were scarified manually before putting on the towel while seeds of $G$ max and RILs were used directly without scarification. The seeds were evaluated on $8^{\text {th }}$ day and germination percentage was recorded on the basis of normal seedlings. Genotypes having $\geq 70 \%$ and $<70 \%$ germination were registered as 'good' and 'poor' storers, respectively, as per Indian Minimum Seed Certification Standards (IMSCS) (Tunwar and Singh, 1988). Germination percentage was recorded separately of freshly harvested seeds and those of stored for one, two and three years under ambient conditions.

To understand the relationship between seed longevity and seed coat traits, electrolyte conductivity tests were performed on a set of 40 contrasting (good and poor storers) G. max genotypes (Supplementary Table 2) as per Anon (2013) with minor modifications. Three replications of 50 seeds were soaked in $250 \mathrm{ml}$ of double distilled water at $25^{\circ} \mathrm{C}$ for $24 \mathrm{hr}$. The seed leachates were collected in $250 \mathrm{ml}$ beaker and the EC was measured at room temperature with a conductivity bridge (HennaModel 13502) and expressed as $\mu \mathrm{S} / \mathrm{cm} / \mathrm{g}$ seed. The EC was tested for the freshly harvested as well as 6 -months stored seeds separately to identifying promising genotypes for better storability.

To measure the kinetics of water uptake pattern (Hahalis and Smith, 1997), seeds of 30 genotypes comprising of 20-soft seeded (10 good-storer $G$ max genotypes and 10 poor-storer $G$ max genotypes) and 10 hard-seeded ( $G$ soja and $G$ tomentella) genotypes were selected (Supplementary Table 3). Three replications of $2 \mathrm{~g}$ seeds were soaked in $25 \mathrm{ml}$ of distilled water at about $25^{\circ} \mathrm{C}$ and their weight was recorded at every two hours' interval up to 24 hours. The rate of water uptake was calculated as percent increase over the initial weight of seeds over the time.

\section{Data Analysis}

All the laboratory-based experiments were conducted by adopting Complete Randomized Design (CRD). The data collected from various experiments were analyzed using SAS software package version 9.4 for calculation of Minimum Significant Difference (MSD), ANOVA for storage studies and Pearson correlation coefficient of different parameters. Correlation analysis was performed using the R function cor() (Wei and Simko, 2017). The K-means cluster analysis was carried out using SYSTAT software version 13.2. Principal Component Analysis (PCA) was performed with Clustvis (Metsalu and Vilo, 2015).

\section{Results}

\section{Genetic variation for seed longevity}

Significant variation was observed among the soybean genotypes for seed germination, periods of storage in ambient conditions and their interactions (Supplementary Table 4). The germination (\%) of the freshly harvested seeds was very high (78$99 \%$ ) with a mean of $94.05 \%$ (Table 1). However, variation in germination was observed in the wild types, cultivated species and the RILs across the storage periods (Table 1). The mean value of germination after one, two and three years of ambient storage 
was $79.51 \%, 52.24 \%$ and $29.18 \%$, respectively (Table 1 and Supplementary Fig. 1), which indicated a decline in the germination of the seeds under ambient storage.

A clear cut difference was observed in germination of the hard-seeded ( $G$ soja and $G$ tomentella) and soft-seeded ( $G$ max and RILs) genotypes. The mean germination (\%) in the hard-seeded genotypes was $88.5 \%, 79.50 \%$ and $70.65 \%$ after one, two and three years of storage, respectively (Table 1). Similarly, the mean germination percentages in the soft-seeded genotypes were $78.12 \%, 48.05 \%$ and $22.80 \%$ after one, two and three year of ambient storage, respectively (Table 1$)$. The three species ( $G$ tomentella, $G$ soja and $G$ max) also found to vary significantly in germination across storage period. Among the three species, $G$ tomentella registered highest germination (94-85\%) followed by G. soja (88-70\%) and G. max (77-18\%) broadly (Fig. 1). During depiction of distribution pattern of germination percentage of all genotypes, across the storage periods through box plots (Supplementary Fig. 1) it was found that the percent germination window was very narrow for fresh seeds (78-99\%) while it was very wide for aged seeds i.e. $10-90 \%$ for two years and 0-85\% for three years stored seeds.

\section{Genetic diversity and principal component analysis}

Multivariate analysis was performed using genetic diversity and principal component analyses with three seed related variables viz., seed germination (mean value over the years), 100-seed weight and seed coat permeability. All the 150 soybean accessions were grouped in to 3 clusters using k-means clustering. Each cluster was found to have varied number of accessions; maximum accessions were found to be in cluster 1(130nos.), followed by cluster 2(18nos.) and cluster 3 (2nos.). The mean value of accessions grouped into each cluster (Table 2) showed that accessions in Cluster-1 had more 100-seed weight and high seed coat permeability whereas Cluster-2 found to have the high seed coat impermeability and high seed germination. The Cluster-3 genotype had highest seed germination and lowest 100-seed weight (Table 2).

PCA was used to eliminate the redundancy in dataset which revealed that all the three seed traits studied have been loaded on to three components; however, major portion of the variance (91.24\%) was explained by the first two components. Out of the three components, only PC1 found to have eigen value >1 (Supplementary Table 5). The first component (PC1) accounted for $74.9 \%$ of the variations and contributed through seed germination and seed coat permeability, rest variation was contributed by PC3 (Supplementary Table 5). Biploting of PC1 and PC2 indicated that seed coat permeability contributed highest to the first two principal components, as soybean accessions dispersed in the groups (Fig. 2). Dispersion of the accessions in biplot indicated the presence of fair amount of genetic diversity in the experimental material.

\section{Association of seed longevity with other seed-related traits}

Association of seed longevity with germination was tested in the selected 150 genotypes. The germination per cent was found to have a positive association with seed longevity. Germination and corresponding longevity was found to be higher in wild species than the cultivated ones even after prolonged storage. On the other hand, the seed coat permeability (\%) found to be in negative correlation (-0.53) with mean germination per cent over the years; with increase in period of storage, the permeability also increased and the viability of the seeds decreased correspondingly (Fig. 3 and Supplementary Table 6). The 100-seed weight trait had positive correlation (0.58) with seed coat permeability, while it had negative correlation (-0.73) with mean germination per cent; thus small seeds had better germination and vice-versa. The relationship found to be holding true over the period of storage (Fig. 3). The seed coat color also found to have some correspondence with viability of the seeds. It appeared that the seeds with black seed coat remain viable for longer period than the seeds with yellow seed coat. Among 22 good storing genotypes identified in cultivated species after two years of storage, 17 appeared to be black and only 5 were yellow seeded. Similarly, out of 10 good storing RILs identified based-on two years of ambient storage, 5 had black seed coat.

\section{Electrical conductance of seed leachates}

As an indirect indicator of longevity and vigour of the seeds, electrical conductance (EC) was measured in the seed leachates of identified contrasting genotypes of G. max. Initial reading of EC for the controlled seeds ranged from $14.69-39.32 \mu \mathrm{S} / \mathrm{cm} / \mathrm{g}$ with a mean of $25.14 \mu \mathrm{S} / \mathrm{cm} / \mathrm{g}$, which got doubled to $51.00 \mu \mathrm{S} / \mathrm{cm} / \mathrm{g}(30.35-88.69 \mu \mathrm{S} / \mathrm{cm} / \mathrm{g})$ after 6 months of storage

(Supplementary Table 2 and Fig 4). There were, however, variations in EC readings among the genotypes of good and poor 
storing categories. Good storing genotypes had lower mean EC values [20.78 $\mu \mathrm{S} / \mathrm{cm} / \mathrm{g}$ (control); $40.37 \mu \mathrm{S} / \mathrm{cm} / \mathrm{g}$ (after six months stored seeds)] than that of the poorly storing genotypes [30.08 $\mu \mathrm{S} / \mathrm{cm} / \mathrm{g}$ (control); $62.45 \mu \mathrm{S} / \mathrm{cm} / \mathrm{g}$ (six months stored seeds)]. DS74 recorded lowest value $(15.20 \mu \mathrm{S} / \mathrm{cm} / \mathrm{g})$ and EC105790 recorded highest value $(30.67 \mu \mathrm{S} / \mathrm{cm} / \mathrm{g})$ at start of seed storage while G2651 recorded lowest value $(30.31 \mu \mathrm{S} / \mathrm{cm} / \mathrm{g})$ and EC105790 recorded highest value $(61.28 \mu \mathrm{S} / \mathrm{cm} / \mathrm{g})$ among the cultivated good storing genotypes. EC471635 registered lowest EC value $(22.23 \mu \mathrm{S} / \mathrm{cm} / \mathrm{g})$ and $(43.25 \mu \mathrm{S} / \mathrm{cm} / \mathrm{g})$, while VLS61 registered highest EC value $39.32 \mu \mathrm{S} / \mathrm{cm} / \mathrm{g}$ and $81.22 \mu \mathrm{S} / \mathrm{cm} / \mathrm{g}$ among the poor storing genotypes at start of seed storage and after six months' storage, respectively (Supplementary Table 2).

\section{Kinetics of water imbibition of seeds}

It was found that the hard-seeded genotypes did not uptake water up to 24hrs. (No change of seed weight), while the soft seeded genotypes (both good and poor storers) started imbibing water within 2 hrs of soaking. The imbibition continued in increasing rate up to $4 \mathrm{hrs}$. after which it imbibed slowly and almost stopped imbibing after $10 \mathrm{hrs}$ of soaking. Genotypic variation in the rate of imbibition was observed. It was found that among the good storing genotypes, rate of imbibition during initial 2 hrs. ranged from $0.56 \mathrm{~g} / \mathrm{h}$ to $0.86 \mathrm{~g} / \mathrm{h}$ as compared to $0.71 \mathrm{~g} / \mathrm{h}-0.93 \mathrm{~g} / \mathrm{h}$ in the poor storing genotypes (Data not presented). Thus, rate of imbibition in the poor storing genotypes was higher than the good storing genotypes (Fig. 5).

\section{Identification of good and poor storers}

In this study, out of four groups, G. tomentella found to have maximum seed longevity potential followed by G. soja. Among the annual wilds, $G$ soja accession DC 2008-1 expressed maximum seed longevity, over the years (Table 3). Based on mean germination per cent over the three years of ambient storage and electrical conductance, 10 wild type accessions were identified that maintained more than $70 \%$ germination over others (Table 3). Among the cultivated genotypes, 10 genotypes (e.g. AMSS34, EC1023, DS74, etc.) were identified that maintained more than 70\% germination up to 2 years of ambient storage; however, none of such genotypes had $70 \%$ germination after 3 years of ambient storage. Similarly, ten genotypes with least viability during storage have also been identified, which was dominated by the cultivated type only (Table 3). Among the RILs, the RIL \# 2-6-2, 234-4 and $4-11-4$ showed $75 \%, 70 \%$ and $73 \%$ germination after three year of storage and identified as good storers.

Further, out of 150 genotypes tested, 20 wild type accessions, 25 RILs and 87 cultivated genotypes showed $>70 \%$ germination after one year of ambient storage (Supplementary Fig. 2). Such genotypes can be classified as 'good storer'. After two years of storage, 17 wild type accessions, 10 RILs and 22 cultivated genotypes met the standard to be called as 'good storer'. After three years of storage under ambient condition, 14 wild type accessions and 3 RILs qualified to be called as 'good storer'; however, none of the cultivated type genotype could meet the standard of minimum germination (Supplementary Fig. 2). Thus, the study could identify a set of 17 genotypes that maintained $>70 \%$ germination across three years of storage (good storers) viz., DC 2008-1, PI 464925-A, PI 424079, PI 366120, 2-6-2, 2-34-4 etc. Similarly, a set of 18 genotypes were identified that had $<70 \%$ germination over three years of storage (poor storer) viz., VLS-61, DSB-19, AMS56, MAUS164 etc. Such genotypes would be useful to study inheritance of the trait through hybridization.

\section{Discussions}

Poor longevity of the soybean seeds poses serious problem in seed market and cause considerable production losses as it affects seed and seedling vigour, crop stand in the field and ultimately the seed yield (Zhang et al. 2019). Therefore, improving seed storability in soybean is important to increase overall crop production (Dargahi et al. 2014). Wild species of soybean are excellent reservoir of longevity-related genes and hence needs to be used in breeding program to introgress this trait in cultivated soybean (Zhou et al. 2010; Talukdar et al. 2016; Kumar et al. 2019a).

In the present investigation, genotypes varied for storage potential; the wild species (G. soja and G. tomentola) maintained higher mean germination per cent (88.5\%) after one year of storage than the cultivated soybean (G. max) (76.53\%). Hosamani et al. (2013) also reported around $79 \%$ mean germination after one year of storage in an investigation of 33 diverse G. max genotypes. Sooganna et al. (2016) reported observance of $79 \%$ germination after eight month of storage of 20 soybean genotypes. Thus, genetic makeup of soybean genotypes essentially determines the viability of the seeds during storage. After 
two year of storage, barring a few, most of the cultivated genotypes lost viability to the tune of about $56 \%$. Nevertheless, 22 genotypes were identified that maintained more than $70 \%$ germination even after 2 years of ambient storage. Kumar (2005) also identified 104 good storing genotypes after two year of storage in ambient storage conditions during screening of $693 \mathrm{G}$. max accessions. Loss of germination was more conspicuous after three years of storage. As a result, none of the $G$. max genotypes maintaining $>70 \%$ germination could be identified; however, a few genotypes viz., DS74, AMS34, EC1023, UPSL163, UPSL291 etc. recorded more than $60 \%$ germination. Saman et al. (2014) also observed similar kind of result (65\% germination) in two genotypes i.e. Williams and L17, after 30 months of storage.

It was observed that the wild type genotypes lived long; however, the genotypes also had genetic variations for the seed viability traits. Among the twenty accessions, germination after three years of storage ranged from $70-85 \%$. This variation was contributed by primarily by genetic makeup of wild genotypes rather than hard seed coat, as all the $G$. soja accessions had similar hard seed coat (Chandra et al. 2017). Genetic variation for seed longevity within G. soja was reported previously by Zhou et al. (2010) and Talukdar et al. (2016). Zhou et al. (2010) observed variation in the ranges of $100 \%-28 \%$ and $100 \%-9 \%$ in G. soja accessions namely DS and QN respectively, after 10 years of storage. Talukdar et al. (2016) recorded seed viability in range of $0 \%-50 \%$ after 7 years of ambient storage during investigation of 29 G. soja accessions. The RILs with permeable seed coat derived from G. soja $\times$ G. max demonstrated the genetic potential of the wild type in enhancing the seed viability of the soybean seeds. The wild-type parent of RILs i.e. G. soja accession DC 2008-1 showed $95 \%, 89 \%$ and $83 \%$ germination after one, two and three years of ambient storage, respectively, while cultivated parent i.e. G. max cv. DS9712 recorded $85 \%, 52 \%$ and $11 \%$ germination after one, two and three years of storage, respectively. RILs derived from this cross showed average seed viability of $84.77 \%$ (77\%-95\%), 65.20\% (35\%-85\%) and 41.75\% (3\%-75\%) after one, two and three years of storage, respectively. This observation revealed that soft-seeded RILs showed germination up to $75 \%$ even after 3 years of storage due to genes introgressed from the wild-type parent rather than hard-seededness per se.

In this study, the 100-seed weight of the tested genotypes ranged from 0.53-13.13g with a mean of $6.51 \mathrm{~g}$ (Table 1). Among the genotypes, lowest 100-seed weight was recorded for the wild type accession of $G$ tomentella $(0.53 \mathrm{~g})$ and the highest was recorded for the cultivated genotype Dsb 19 (13.13g). Seeds of RILs were also small but larger than the wild types and its 100seed weight ranged from $1.18 \mathrm{~g}$ (RIL\#7-28-2) to $3.95 \mathrm{~g}$ (RIL\#34-30-1) with mean of $2.30 \mathrm{~g}$ (Table 1). Seeds of the cultivated genotypes, however, appeared to be small, medium and large (Chandra et al. 2017). As per DUS guidelines (2009), seeds of the wild type accessions and RILs were grouped as small, while the cultivated genotypes had small (84 nos.), medium (19nos.) and large (2 nos.). The small seed size and black seed coat colour may contribute towards better seed longevity (Hosamani et al. 2013; Sooganna et al. 2016). However, RILs with better seed viability and acceptable seed size (2.8 g -3.8 g) and non-black (green-yellow) seed coat was also obtained in this study. Thus, the G. soja can contribute towards enhancing greater seed longevity in cultivated soybean. In Rice, Xue et al. (2008) and Jiang et al. (2011) identified QTLs for storability using wild genotypes and developed improved breeding line by introgressing these QTLs. In India, wild soybean germplasm has been least used in genetic studies and breeding programs (Yashpal et al. 2015). Successful utilization of wild types to improve the traits of cultivated type has been reported in tomato (Tanksley et al. 1996), soybean (Concibido et al. 2003) and rice (Gaikwad et al. 2014). This study demonstrates the potential of wild-type germplasm as source of viability-related gene(s) to improve the storability of elite cultivars.

Location of seed production and packaging materials used for seeds storage also affects seed viability. In the present study, use of water proof seed envelop, careful manual harvesting and geographical location of New Delhi (Agarwal, 1980) might have contributed towards seed viability. Waterproof seed envelopes results into enhanced storability compared to the cloth bags in soybean (Gupta and Aneja, 2004). Color of the seed coat seemed to influence storability of soybean seeds in some genotypes, if not all. Usually, wild type genotypes are black and stores better whereas, cultivated genotypes are primarily yellow and stores poorly. Among the 22 good storers identified in this study, $72 \%$ were black and rest $28 \%$ were yellow (Supplementary Fig. 3). Similar findings have also been reported by Hosamani et al. (2013) and Sooganna et al. (2016) in soybean. The black seeds show more storability due to activity of some free fatty acids and phenolic compounds (Liu et al. 2017). The seed coat permeability found to have negative correlation with seed viability, which is in agreement with Nacer et al. (2017) and Kumar et al. (2019a). The seed size has positive correlation with mechanical damage and seed coat permeability (Mugnisjah et al. 1987; Chandra et al. 2017) and negative correlation with seed viability (Tiwari and Joshi 1989; Kumar et al. 2019a). The larger seeds 
found to have more seed coat permeability (Chandra et al. 2017). The better quality maintained by the smaller soybean seeds may also be attributed to its ability to escape injury caused due to mechanical damage during harvesting, handling and processing (Robert, 1972).

Based on seed coat permeability (\%), the wild groups and the cultivated types-RIL groups appeared to be different from one another. On the basis of 7 days 'slow imbibition' protocol, the seed coat of the $G$ soja accessions (except DC2008-1) was found to be impermeable; however, the seed coat of G. tomentella and DC 2008-1(G. soja) appeared to be intermediate-permeable with imbibition of $66 \%$ and $36 \%$, respectively. The seed coat of all the genotypes of G. max and the RILs were found to be permeable with imbibition ranging from $92-100 \%$ (Chandra et al. 2017). The water uptake in the soft-seeds was very rapid in the first few hours of imbibition followed by a lag phase. The rate of imbibition, however, varied considerably among the soft seeded genotypes. Rapid imbibition may lead to hydration damage causing dip in germination percentage among the poor storing genotypes. The good storing genotypes, on the other hand, maintained slow imbibition at the initial phase thus preventing reduction in viability of the seeds. Therefore, seeds that absorb moisture slowly might also be expected to have better storability.

In this study, it was found that electrolyte leakage as measured through EC had higher values in the poor storing genotypes than the good ones. A significant linear relationship between electrolyte leakage from imbibed seed and germinability has been reported in soybean (Dadlani and Agrawal, 1983; Sooganna et al. 2016). Sano et al. (2015) reported that loss of seed viability is often associated with oxidation of various bio-molecules viz., glucose, oils and fatty acids etc. Thus, electrical conductance from seed leachates can be considered as good marker for screening soybean genotypes for seed storability.

Knowledge of genetic divergence in the available soybean species is of immense importance for selecting the parents to be used in breeding programme including wide hybridization for obtaining desirable genetic recombination for seed longevity and associated traits. The K-means cluster analysis grouped the genotypes in to three clusters. The genotypes from the cluster 1 (soft-seeded) and cluster 2(hard-seeded) were contrasting regarding seed coat permeability, 100-seed weight and germination (\%). These genotypes can be used to develop mapping population for understanding genetics of these traits. Further, wild annual i.e. DC 2008-1 from cluster 3 can be used to introgress intermediate seed coat impermeability in the elite cultivars to improve their viability. PCA enable us to assess the relative contribution of different components to the total divergence together with nature of forces operating at intra- and inter-cluster levels (Sharma et al. 2009). In the current study, first two components explained $>90 \%$ of the total variation. In the first two PCs, maximum percentage of variation was contributed by seed coat permeability. Genotypes far from the origin exhibited more variability for seed related traits and could be utilized as diverse parents in broadening the genetic base of soybean through hybridization. Similar type of divergence studies was also conducted by Naik et al. (2016) in G. max lines to identify the diverse lines.

\section{Conclusion}

One of the major obstacles for soybean cultivation in India is the non-availability of good quality seed and maintenance of prescribed level of seed germination and vigor after harvest until the planting of succeeding season. The information generated in this study could be effectively utilized for screening of soybean genotypes for their storage behavior. Identified good storer genotypes could be used to introgress seed storability trait in the elite cultivars as well to develop mapping population by hybridizing with the poor storers to understand the genetics of the storability traits.

\section{Declarations}

\section{Compliance with ethical standards}

Funding: Authors are grateful to the National Agricultural Science Fund, ICAR, New Delhi for funding the program.

Conflicts of interest: The authors declare that they have no conflict of interest.

Author contributions: Conceptualization of research (AT, SC); Designing of the experiments (AT, SC); Contribution of experimental materials (SKL, AT, NSS); Execution of lab experiments and data collection (SC, RRY, YT, MS); Analysis of data and interpretation 
(SC, YT); Preparation of the manuscript (SC, AT).

Acknowledgements: First author is grateful to the UGC, New Delhi for Junior Research Fellowship (JRF) during his doctoral study and authors are grateful to the Collaborative Outstation Research Centre-Sipani Krishi Anusandhan Farm (SKAF), Mandsour, MP for providing the seed materials of the wild soybean accessions.

\section{References}

Adsul AT, Chimote VP, Deshmukh MP (2018) Inheritance of seed longevity and its association with other seed-related traits in soybean (Glycine max). Agri. Res. 7(2):105-111.https://doi.org/10.1007/s40003-018-0297-7

Agarwal PK (1980) Relative storability of seeds of ten species under ambient conditions. Seed Res. 8: 94-99

Ananymous (2013) International Rules for Seed Testing published by The International Seed Testing Association P O Box 308 8303 Bassersdorf CH-Switzerland

Bellaloui N, Smith JR, Mengistu A, Ray JD, Gillen AM (2017) Evaluation of exotically-derived soybean breeding lines for seed yield, germination, damage, and composition under dryland production in the midsouthern USA. Frontiers in plant science 8:176. https://doi.org/10.3389/fpls.2017.00176

Bhatia VS (1996) Seed longevity as affected by field weathering and its association with seed coat and pod characters in soybean. Seed Res. 24: 82-87

Chandra S, Taak Y, Rathod DR, Yadav RR, Poonia S, Sreenivasa V, Talukdar A (2020) Genetics and mapping of seed coat impermeability in soybean using inter-specific populations. Physiology and Molecular Biology of Plants 26(11):2291-9. https://doi.org/10.1007/s12298-020-00906-y

Chandra S, Yadav RR, Poonia S, Yashpal, Rathod DR, Kumar A, Lal SK, Talukdar A (2017) Seed coat permeability studies in wild and cultivated species of soybean. International Journal of Current Microbiology and Applied Science 6(7): 2358-2363.

https://doi.org/10.20546/ijcmas.2017.607.279

Dadlani M, Agrawal P K (1983) Mechanism of soybean seed deterioration. Plant Physiol. Biochem. 10: 23-30.

Dargahi H, Tanya P, Srinives P (2014) Mapping of the genomic regions controlling seed storability in soybean (Glycine max L.). J. Genet. 93(2): 365-370. https://doi.org/10.1007/s12041-014-0381-0

Gaikwad KB, Singh N, Bhatia D, Kaur R, Bains NS, Bharaj TS, Singh K (2014) Yield-enhancing heterotic QTL transferred from wild species to cultivated rice Oryza sativa L. PLoS One, 9(6): e96939

Gupta PC, Aneja KR (2004) Seed deterioration in soybean varieties during storage physiological attributes. Seed Res.32 (1): $26-$ 32

Hahlis DA, Smith ML (1997) Basic and applied aspects of seed biology. Proceedings of the fifth International workshop on seeds, sept. 10-15, 1995, Reading, U.K. pp 507-513

Hang NT, Lin Q, Liu L, Liu X, Liu S, Wang W, Li L, He N, Liu Z, Jiang L, Wan J (2015) Mapping QTLs related to rice seed storability under natural and artificial aging storage conditions. Euphytica 203(3):673-81. https://doi.org/10.1007/s10681-014-1304-0

Hosamani J, Kumar MB, Talukdar A, Lal SK and Dadlani M (2013) Molecular characterization and identification of candidate markers for seed longevity in soybean [G/ycine max (L.) Merill]. Indian J Genet. 73(1): 64-71.

Jiang W, Lee J, Jin YM, Qiao Y, Piao R, Jang SM, Woo MO, Kwon SW, Liu X, Pan HY, Du X (2011) Identification of QTLs for seed germination capability after various storage periods using two RIL populations in rice. Molecules and cells 31(4): 385-392. https://doi.org/10.1007/s10059-011-0049-z 
Kuchlan MK, Dadlani M, Samuel DVK (2010) Seed coat properties and longevity of soybean seeds. Journal of New Seeds 11: 239-249.

Kumar A (2005) Studies on storability and vigour parameters in soybean. MSc Thesis. Division of Seed Science and Technology, ICAR-IARI, New Delhi

Kumar A, Chandra S, Talukdar A, Yadav RR, Saini M, Poonia S, Lal SK (2019a) Genetic studies on seed coat permeability and viability in RILs derived from an inter-specific cross of soybean [Glycine max (L.) Merrill]. Indian J. Genet 79(1): 48-55

Kumar A, Talukdar A, Yadav RR, Poonia S, Ranjan R, Lal SK (2019b) Identification of QTLs for seed viability in soybean [Glycine $\max ($ L.) Merill]. Indian J. Genet 79(4): 713-718

Liu J, Qin WT, Wu HJ, Yang CQ, Deng JC, Iqbal N, Liu WG, Du JB, Shu K, Yang F, Wang XC (2017) Metabolism variation and better storability of dark-versus light-coloured soybean (Glycine max L. Merr.) seeds. Food chemistry 223:104-113. https://doi.org/10.1016/j.foodchem.2016.12.036

Metsalu T, Vilo J (2015) Clustvis: a web tool for visualizing clustering of multivariate data using Principal Component Analysis and heat map. Nucleic Acids Research 43(W1):W566-W570. doi: 10.1093/nar/gkv468.

Mugnisjah WQ, Shimano I, Matsumoto S (1987) Studies on the vigour of soybean seeds II. Varietal differences in seed coat quality and swelling components on seed during moisture imbibition. Journal of the Faculty of Agriculture, Kyushu University 13: 227-234

Naik SM, Madhusudan K, Motagi BN, Nadaf HL (2016) Diversity in soybean (Glycine max) accessions based on morphological characterization and seed longevity characteristics. Progressive Research-An International Journal, 11(03): 377-381.

Rathod DR, Jyoti D, Anil K, Keya M, Deepika C, Subhash C, Lal SK, Akshay T (2015) Genomic variation studies in Glycine max and Glycine soja using SSR markers. Curr. Sci. 109: 1929-1931.

Roberts EH (1972) Viability of Seeds. Chapman and Hall, London, pp. 448

Saman S, Heidari H, Abad S, Hamidi A, Ghorban N, Mohammadi AM (2014) Evaluation of soybean seed quality under long term storage. International Journal of Biosciences 5: 214-219. Available at: http://innspub.net/wp-content/uploads

Sano N, Rajjou L, North HM, Debeaujon I, Marion-Poll A, Seo M (2015) Staying alive: molecular aspects of seed longevity. Plant Cell Physiol 57(4):660-674. https://doi.org/10.1093/pcp/pcv186

Sharma MK, Mishra S and Rana NS (2009) Genetic divergence in French bean (Phaseolus vulgaris L.) pole type cultivars. Legume Res. 32: 220-223.

Sooganna S, Jain SK, Bhat KV, Amrit L, Lal SK (2016) Characterization of soybean (Glycine max) genotypes for seed longevity using SSR markers. Indian Journal of Agricultural Sciences 86(5):605-10.

Talukdar A, Chandra S, Yashpal, Rathod DR, Yadav RR, Kumar A, Poonia S, Lal SK, Sipani NS (2016) Seed viability in Soybean: Donor identified and RILs Developed. In: Abstracts of $1^{\text {st }}$ International Agro biodiversity Congress, held from November 6-9, 2016 at NASC Complex, New Delhi, India, pp. 187

Tanksley SD, Grandillo S, Fulton TM, Zamir D, Eshed Y, Petiard V, Lopez J, Beck-Bunn T (1996) Advanced backcross QTL analysis in a cross between an elite processing line of tomato and its wild relative L. pimpinellifolium. Theor. Appl. Genet. 92: $213-224$. https://doi.org/10.1007/BF00223378

Tiwari SP, Joshi HJ (1989) Correlation and path analysis for seed quality characters in soybean. Oil Seed Res 16: 51-57. 
Tunwar NS, Singh SV (1988) Indian Minimum Seed Certification Standards Central Seed Certification Board, Department of Agri and Cooperation, Ministry of Agriculture, GOI, New Delhi, India

Wei T and Simko V (2017) R package 'corrplot': Visualization of a Correlation Matrix (Version 0.84). Available at https://github.com/taiyun/corrplot.

Xue Y, Zhang SQ, Yao QH, Peng RH, Xiong AS, Li X, Zhu WM, Zhu YY, Zha DS (2008) Identification of quantitative trait loci for seed storability in rice (Oryza sativa L.) Euphytica 164(3): 739-744. https://doi.org/10.1007/s10681-008-9696-3

Zhang X, Hina A, Song S, Kong J, Bhat JA, Zhao T(2019) Whole-genome mapping identified novel "QTL hotspots regions" for seed storability in soybean (Glycine max L.). BMC genomics 20(1):1-14. https://doi.org/10.1186/s12864-019-5897-5

Zhou S, Sekizaki H, Yang Z, Sawa S, Pan J(2010) Phenolics in the seed coat of wild soybean (Glycine soja) and their significance for seed hardness and seed germination. Journal of agricultural and food chemistry 58(20): 10972-10978.

Zihad M (2013) Physiological Phenotyping of Soybean (Glycine max L. Merrill) genotypes for seed longevity. M.Sc. Thesis. Division of Seed Science and Technology, ICAR-IARI, New Delhi

\section{Tables}

Table 1: Descriptive statistics of seed germination of soybean accessions across the years

\begin{tabular}{|c|c|c|c|c|c|c|c|c|c|c|c|c|}
\hline & \multicolumn{2}{|c|}{100 SW (g) } & \multicolumn{2}{|l|}{ G0 (\%) } & \multicolumn{2}{|l|}{ G1 (\%) } & \multicolumn{2}{|l|}{ G2 (\%) } & \multicolumn{2}{|l|}{ G3 (\%) } & \multicolumn{2}{|c|}{ Gmean (\%) } \\
\hline & Mean & Range & Mean & Range & Mean & Range & Mean & Range & Mean & Range & Mean & Range \\
\hline \multicolumn{13}{|l|}{$\begin{array}{l}\text { Hard- } \\
\text { seeded }\end{array}$} \\
\hline $\begin{array}{l}\text { G. } \\
\text { tomentella }\end{array}$ & 0.53 & & 99.00 & & 94.00 & & 91.00 & & 85.00 & & 92.25 & \\
\hline $\begin{array}{l}\text { Glycine } \\
\text { soja }\end{array}$ & 1.26 & $\begin{array}{l}0.56- \\
2.07\end{array}$ & 96.32 & $89-99$ & 88.21 & 77-95 & 78.95 & $68-89$ & 69.89 & $57-83$ & 83.34 & $\begin{array}{l}72.75- \\
91.5\end{array}$ \\
\hline $\begin{array}{l}\text { Total } \\
\text { (hard- } \\
\text { seeded) }\end{array}$ & 1.22 & $\begin{array}{l}0.53- \\
2.07\end{array}$ & 96.45 & 89-99 & 88.55 & 77-95 & 79.50 & $68-91$ & 70.65 & $57-85$ & 83.79 & $\begin{array}{l}\text { 72.75- } \\
92.25\end{array}$ \\
\hline \multicolumn{13}{|l|}{$\begin{array}{l}\text { Soft- } \\
\text { seeded }\end{array}$} \\
\hline $\begin{array}{l}\text { Glycine } \\
\max \end{array}$ & 8.52 & $\begin{array}{l}5.06- \\
13.13\end{array}$ & 93.56 & 78-99 & 76.53 & $48-92$ & 43.96 & $10-81$ & 18.39 & $0-69$ & 58.11 & $\begin{array}{l}36.75- \\
85\end{array}$ \\
\hline RILs & 2.30 & $\begin{array}{l}1.18^{-} \\
3.95\end{array}$ & 94.17 & 87-99 & 84.77 & $72-95$ & 65.20 & $35-85$ & 41.33 & $3-75$ & 71.37 & $\begin{array}{l}54.33- \\
88.16\end{array}$ \\
\hline $\begin{array}{l}\text { Total (soft- } \\
\text { seeded) }\end{array}$ & 7.32 & $\begin{array}{l}1.18- \\
13.13\end{array}$ & 93.68 & $78-99$ & 78.12 & $48-95$ & 48.05 & $10-81$ & 22.80 & $0-75$ & 60.66 & $\begin{array}{l}36.75- \\
88.16\end{array}$ \\
\hline $\begin{array}{l}\text { Total } \\
\text { accessions }\end{array}$ & 6.51 & $\begin{array}{l}0.53- \\
13.13\end{array}$ & 94.05 & 78-99 & 79.51 & $48-95$ & 52.24 & $10-90$ & 29.18 & $0-85$ & 63.75 & $\begin{array}{l}36.75- \\
92.25\end{array}$ \\
\hline
\end{tabular}

100 SW: 100 seed weight/seed index, G0: Germination of freshly harvested seeds, G1: Germination of seeds after one year of storage, G2: Germination of seeds after two year of storage, G3: Germination of seeds after three year of storage, Gmean: mean germination (\%) over the years $(0,1,2,3)$ 


\begin{tabular}{|c|c|c|c|c|c|c|c|c|c|}
\hline \multirow[t]{2}{*}{ Cluster variables } & \multicolumn{3}{|c|}{ Cluster 1} & \multicolumn{3}{|c|}{ Cluster 2} & \multicolumn{3}{|c|}{ Cluster 3} \\
\hline & Mean & Range & SD & Mean & Range & SD & Mean & Range & SD \\
\hline Germination \% (Avg.) & 60.66 & $\begin{array}{l}34.25- \\
89.00\end{array}$ & 12.55 & 82.89 & $\begin{array}{l}72.50- \\
90.75\end{array}$ & 5.07 & 91.88 & $89.75-95.25$ & 1.90 \\
\hline $\begin{array}{l}\text { Seed coat permeability } \\
(\%)\end{array}$ & 99.75 & $91-100$ & 0.96 & 1.00 & $0-7$ & 2.02 & 51.00 & $34-68$ & 16.53 \\
\hline $\begin{array}{l}100 \text { seed } \\
\text { weight }(\mathrm{g})\end{array}$ & 7.32 & $\begin{array}{l}0.94- \\
13.43\end{array}$ & 3.03 & 1.30 & $0.50-2.37$ & 0.45 & 0.55 & $0.43-0.86$ & 0.24 \\
\hline Accessions (No.) & \multicolumn{3}{|c|}{130 (All G. max and all RILs) } & \multicolumn{3}{|c|}{18 (18 G. soja accessions) } & \multicolumn{3}{|c|}{$\begin{array}{l}2(\text { G. tomentella and G. soja DC } \\
2008-1)\end{array}$} \\
\hline
\end{tabular}

Table 3. Details of good storing and poor storing genotypes 


\begin{tabular}{|c|c|c|c|c|c|c|c|}
\hline Genotype & SCC & HSW & $G(0) \%$ & $G(1) \%$ & $G(2) \%$ & $G(3) \%$ & $\mathrm{G}$ (mean) \\
\hline \multicolumn{8}{|c|}{ Good storers* (wild species) } \\
\hline G. tomentola & Black & 0.5312 & 99 & 95 & 90 & 85 & 92.25 \\
\hline DC-2008-1 & Black & 0.5614 & 99 & 95 & 89 & 83 & 91.50 \\
\hline PI-464925-A & Black & 1.178 & 99 & 95 & 86 & 80 & 90.00 \\
\hline PI-464925-B & Black & 0.94 & 98 & 94 & 87 & 75 & 88.50 \\
\hline PI-424079 & Black & 1.301 & 99 & 91 & 84 & 77 & 87.75 \\
\hline PI-522183-B & Black & 1.007 & 99 & 92 & 84 & 74 & 87.25 \\
\hline PI-464889-A & Black & 1.044 & 98 & 94 & 83 & 72 & 86.75 \\
\hline PI-326582-B & Black & 1.178 & 99 & 90 & 81 & 75 & 86.25 \\
\hline PI-407292 & Black & 0.695 & 99 & 89 & 82 & 73 & 85.75 \\
\hline PI-366120 & Black & 1.796 & 97 & 92 & 80 & 73 & 85.50 \\
\hline \multicolumn{8}{|c|}{ Good storers" (cultivated species) } \\
\hline AMSS 34 & Black & 6.135 & 98 & 92 & 81 & 69 & 85.00 \\
\hline DS 74 & Black & 6.96 & 99 & 91 & 79 & 68 & 84.25 \\
\hline USSL-291 & Black & 6.405 & 99 & 86 & 78 & 64 & 81.75 \\
\hline EC 1023 & Yellow & 9.41 & 98 & 88 & 80 & 61 & 81.75 \\
\hline M253 & Black & 6.575 & 99 & 86 & 77 & 60 & 80.50 \\
\hline UPSL 163 & Black & 6.18 & 95 & 84 & 75 & 64 & 79.50 \\
\hline DS MM 64 & Black & 7.945 & 96 & 85 & 76 & 58 & 78.75 \\
\hline UPSL-736 & Yellow & 7.595 & 94 & 86 & 76 & 58 & 78.50 \\
\hline EC105790 & Yellow & 6.625 & 99 & 86 & 74 & 53 & 78.00 \\
\hline UPSL-34 & Black & 5.06 & 98 & 85 & 73 & 55 & 77.75 \\
\hline \multicolumn{8}{|c|}{ Good storers* (RILs) } \\
\hline $2-6-2$ & Black & 2.85 & 100 & 93 & 85 & 75 & 88.17 \\
\hline $4-11-4$ & Black & 3.81875 & 99 & 94 & 81 & 73 & 86.83 \\
\hline $2-34-5$ & green Yellow & 2.6575 & 99 & 95 & 84 & 67 & 86.25 \\
\hline $2-34-4$ & green Yellow & 2.374 & 99 & 93 & 76 & 70 & 84.41 \\
\hline $14-3-5$ & Black & 1.93475 & 96 & 86 & 77 & 65 & 80.83 \\
\hline \multicolumn{8}{|l|}{ Poor storers\# } \\
\hline DSB-19 & Yellow & 13.13 & 88 & 48 & 11 & 0 & 36.75 \\
\hline EC-471635 & Brown & 9.6 & 78 & 62 & 10 & 0 & 37.50 \\
\hline PK 472 & Yellow & 10.615 & 88 & 60 & 15 & 1 & 41.00 \\
\hline PS-1480 & Yellow & 10.075 & 88 & 51 & 26 & 3 & 42.00 \\
\hline MAUS-164 & Yellow & 12.81 & 89 & 65 & 19 & 0 & 43.25 \\
\hline
\end{tabular}




\begin{tabular}{|llllllll|}
\hline MACS-450 & Yellow & 10.615 & 82 & 70 & 19 & 2 & 43.25 \\
\hline PS-1503 & Yellow & 12.027 & 90 & 63 & 22 & 0 & 43.75 \\
\hline G-2144 & Green yellow & 6.725 & 88 & 70 & 19 & 0 & 44.25 \\
\hline VLS-61 & Yellow & 8.495 & 90 & 68 & 16 & 3 & 44.25 \\
\hline DSB-21 & Yellow & 12.655 & 90 & 60 & 21 & 7 & 44.50 \\
\hline
\end{tabular}

*identified based on mean germination and EC leaching; "Identified based on mean germination

SCC: Seed coat colour; HSW: 100 seed weight; G0: germination of fresh seeds; G1: germination after 1-year storage; G2: germination after 2-year storage; G3: germination after 3-year storage

\section{Figures}

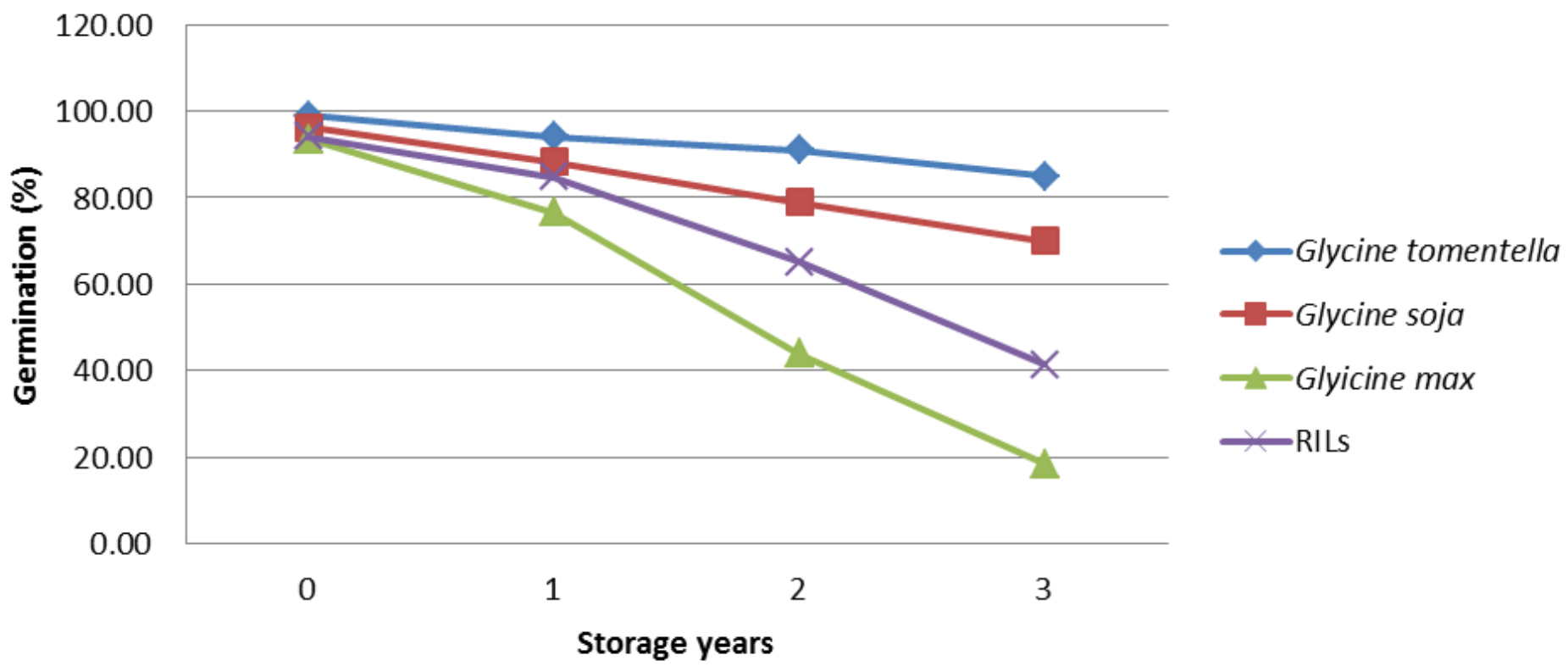

Figure 1

Aging pattern of seed viability of soybean accessions over the years $(0,1,2,3$ on horizontal axis are years of storage) 


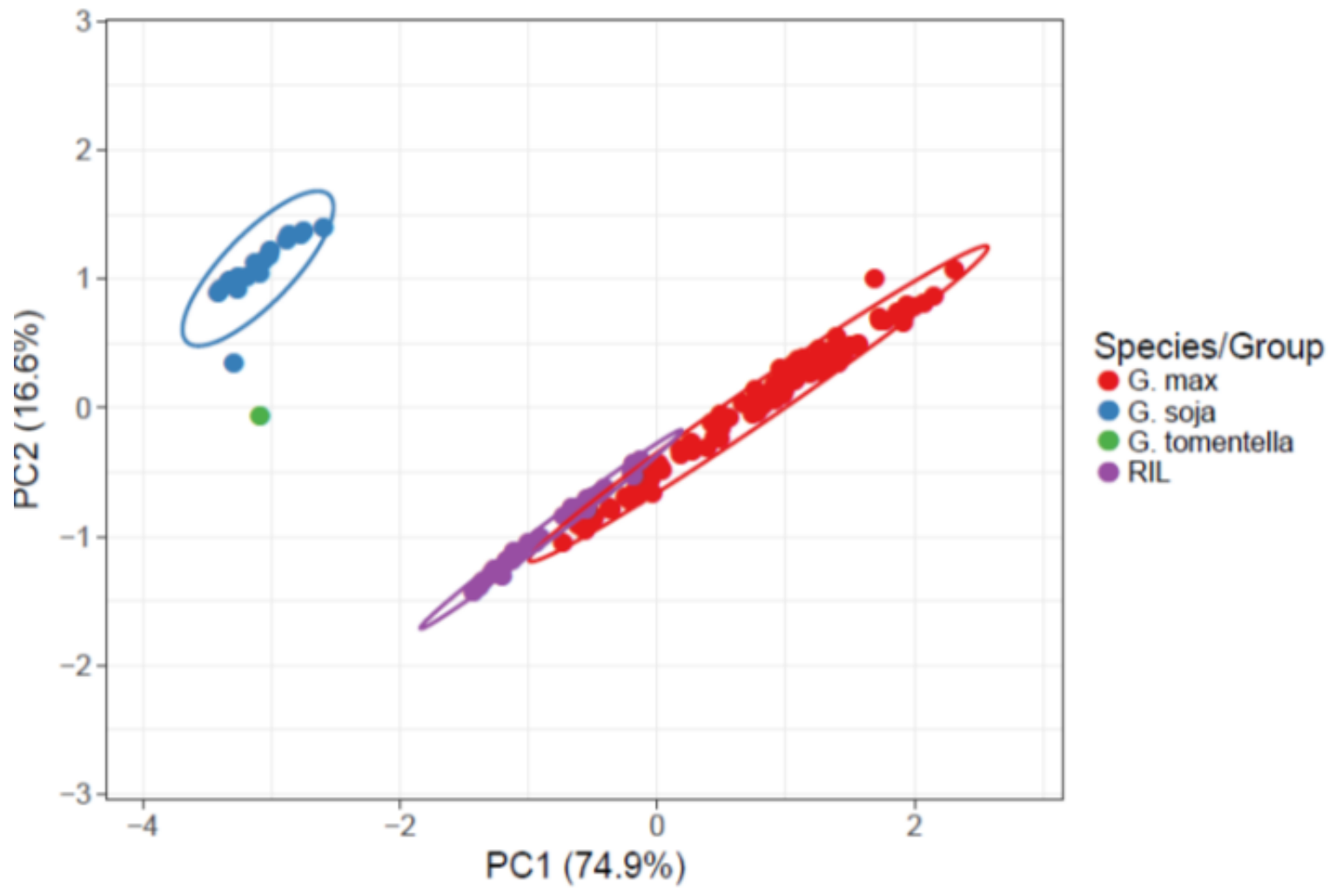

Figure 2

Bi-plotting of different seed variables loaded on PC 1 and PC 2

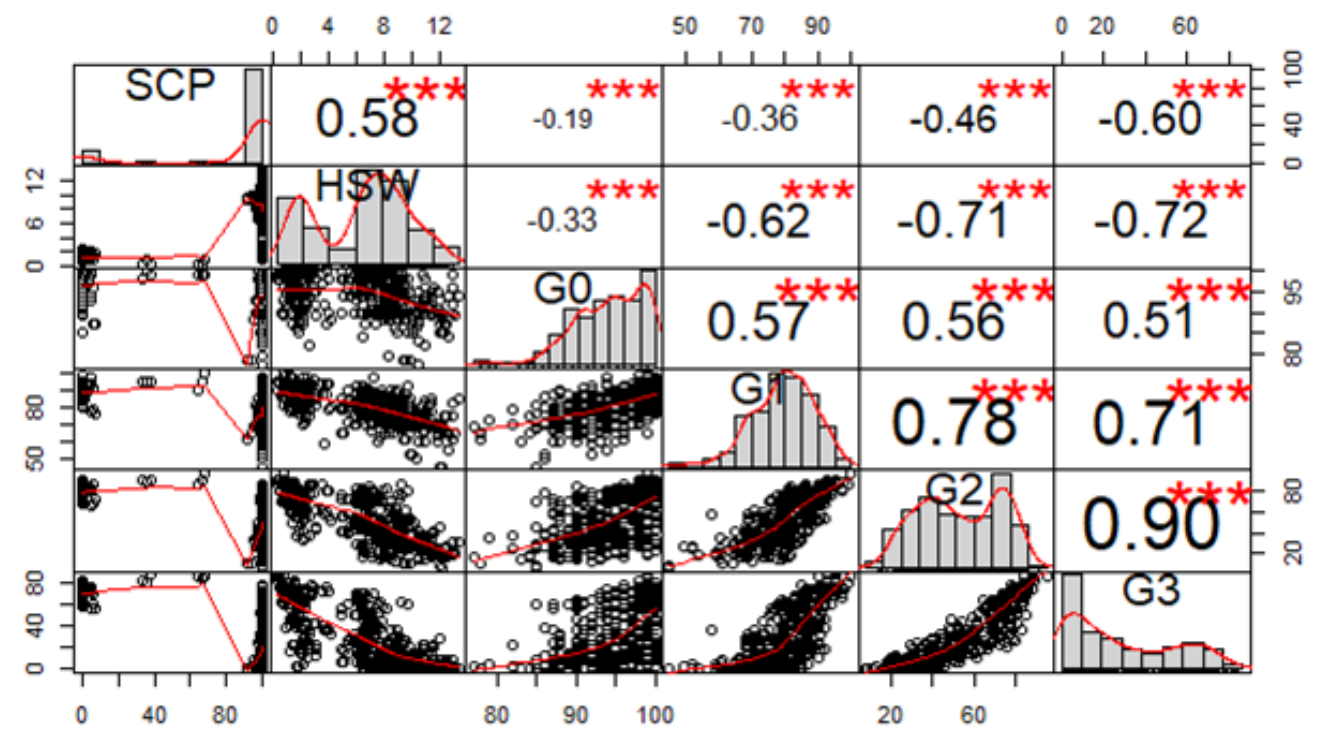

Figure 3

Graphical depiction of correlation among the seed traits in soybean genotypes ( ${ }^{\star}{ }^{2}$ Correlation is significant at the 0.01 level; HSW: 100 seed weight; SCP: Seed coat permeability; G0, G1, G2, G3: Germination (\%) after 0, 1, 2, and 3 years of storage respectively) 


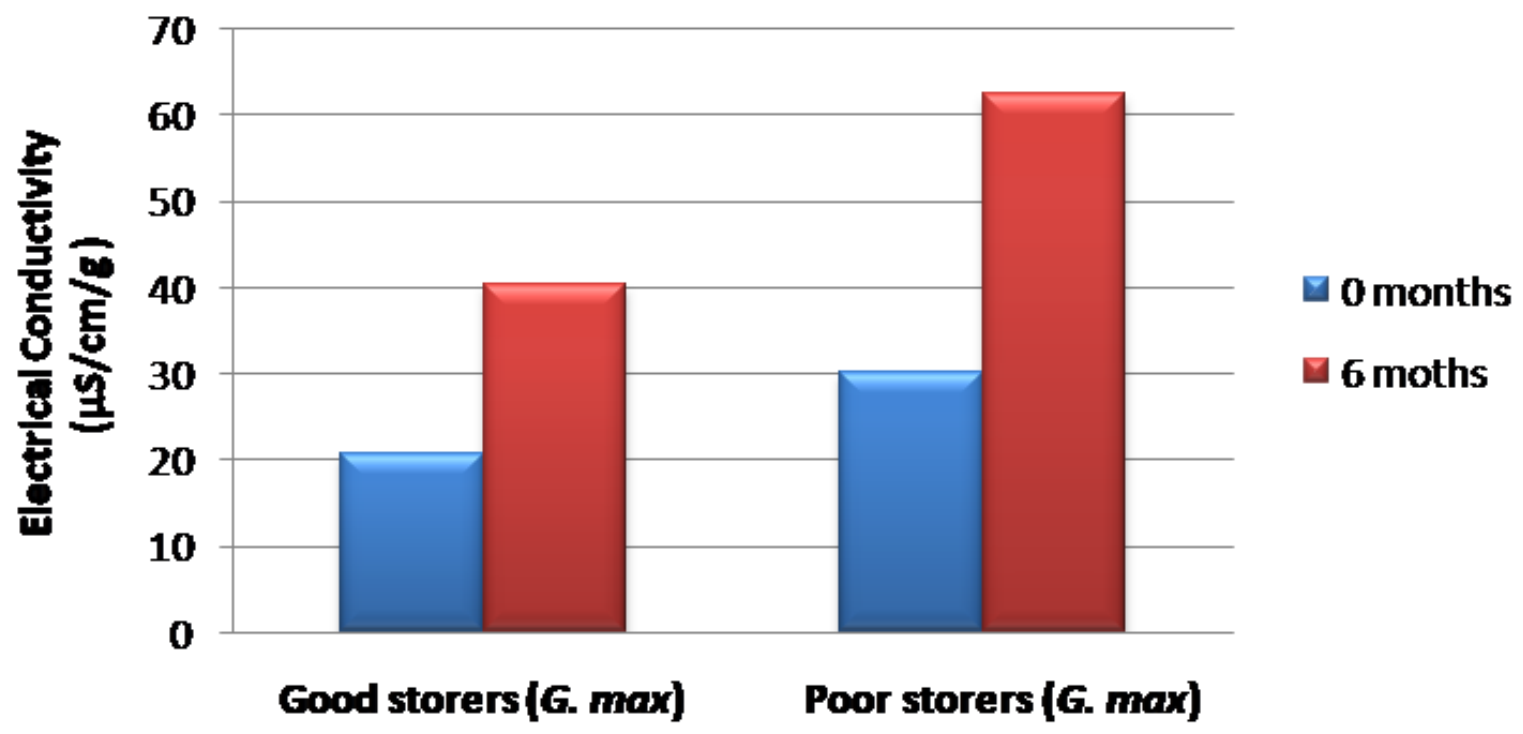

Figure 4

Electrical conductance from seed leachates on good and poor storers during storage



Figure 5

Kinetics of water uptake in soybean genotypes (A: soft seeded good storers B: soft seeded poor storers C: Hard seeded genotypes)

\section{Supplementary Files}

This is a list of supplementary files associated with this preprint. Click to download.

- Supplementrymaterials.docx 